Purdue University

Purdue e-Pubs

CTRC Research Publications

Cooling Technologies Research Center

7-1-2005

\title{
An Experimentally Validated Thermo-mechanical Model for the Prediction of Thermal Contact Conductance
}

\author{
Vishal Singhal \\ Paul J.Litke \\ Anthony F. Black \\ S V. Garimella \\ Purdue University, sureshg@purdue.edu
}

Follow this and additional works at: http://docs.lib.purdue.edu/coolingpubs

Singhal, Vishal; Litke, Paul J.; Black, Anthony F.; and Garimella, S V., "An Experimentally Validated Thermo-mechanical Model for the Prediction of Thermal Contact Conductance" (2005). CTRC Research Publications. Paper 69.

http://dx.doi.org/10.1016/j.ijheatmasstransfer.2005.06.028

This document has been made available through Purdue e-Pubs, a service of the Purdue University Libraries. Please contact epubs@purdue.edu for additional information. 


\title{
An Experimentally Validated Thermo-Mechanical Model for the Prediction of Thermal Contact Conductance ${ }^{\S}$
}

\author{
Vishal Singhal, Paul J. Litke, Anthony F. Black and Suresh V. Garimella ${ }^{\text {qI }}$ \\ Cooling Technologies Research Center, School of Mechanical Engineering, \\ Purdue University, West Lafayette, Indiana 47907-2088 USA
}

Keywords: Thermal contact conductance, electronics cooling, constriction resistance, surface deformation analysis, surface characterization

\begin{abstract}
A predictive model for estimating thermal contact conductance between two nominally flat metallic rough surfaces has been developed and experimentally validated. The predictive model consists of two complementary parts, the first of which is a surface deformation analysis to calculate the actual area of contact for each contact spot, while the second accounts for the effects of constriction resistance and gas gap conductance between the contacting surfaces. A surface characterization technique is developed which generates an equivalent 3-D surface profile from multiple 2-D profiles and determines the unique wavelengths of importance for the surface deformation and constriction resistance models. For given surface profiles and material properties of two contacting surfaces, and a specified contact pressure, the surface characterization technique filters out non-essential wavelengths on the surface, after which the surface deformation analysis calculates the deformation and contact area of each contacting asperity by considering three different modes of deformation, namely, elastic, elastic-plastic, and plastic. The constriction resistance model is then used to calculate the constriction resistance for each contacting asperity based on the area of contact and radius of curvature of the asperity. The constriction resistance values for all the contacting asperities are then used to calculate the total thermal contact conductance. An experimental facility has also been constructed to measure thermal contact conductance of interfaces to verify the results of the predictive model. Good agreement has been found between the model predictions and experimental measurements, validating the modeling approach.
\end{abstract}

\footnotetext{
${ }^{\S}$ Submitted for publication in International Journal of Heat and Mass Transfer, July 2004, and in revised form, June 2005

${ }^{\mathbb{A}}$ Author to whom correspondence should be addressed, tel.: 765-494-5621, e-mail: sureshg@ecn.purdue.edu
} 


\section{NOMENCLATURE}

\begin{tabular}{|c|c|}
\hline$a$ & Radius of contact of an asperity (m) \\
\hline$A$ & Area of contact $\left(\mathrm{m}^{2}\right)$ \\
\hline$b$ & Radius of heat flux tube (m) \\
\hline$c$ & Intercept in temperature curve fit equations $(\mathrm{K})$ \\
\hline$d$ & Separation between the mean planes of two surfaces $(\mathrm{m})$ \\
\hline$d_{i}$ & Test column diameter $(\mathrm{m})$ \\
\hline E & Elastic modulus $(\mathrm{Pa})$ \\
\hline$h$ & Thermal contact conductance $(\mathrm{W} / \mathrm{K})$ \\
\hline$k$ & Thermal conductivity (W/m-K) \\
\hline$l$ & Height of an asperity (m) \\
\hline$m$ & Slope in temperature curve fit equations $(\mathrm{K} / \mathrm{m})$ \\
\hline$p$ & Contact pressure $(\mathrm{Pa})$ \\
\hline$Q$ & Total heat flow (W) \\
\hline$r$ & Generic quantity for general uncertainty analysis \\
\hline$R$ & Radius of curvature of an asperity (m) \\
\hline$R_{a}$ & Centerline Average Surface Roughness (m) \\
\hline$t$ & Non-dimensional parameter (dimensionless) \\
\hline$T$ & Temperature (K) \\
\hline$\Delta T$ & Temperature difference $(\mathrm{K})$ \\
\hline$U_{r}$ & Uncertainty in quantity $r$ \\
\hline$x$ & Axial location (m) \\
\hline$Y$ & Yield stress $(\mathrm{Pa})$ \\
\hline $\mathrm{z}$ & Height of the mean plane of a surface (m) \\
\hline \multicolumn{2}{|l|}{ Subscripts } \\
\hline$*$ & Equivalent value \\
\hline 1 & Material 1 \\
\hline 2 & Material 2 \\
\hline$a, b, c, d, e, f, g, h$ & Reference labels for surfaces of column elements \\
\hline apparent & Apparent value \\
\hline avg & Average \\
\hline con & Constriction \\
\hline contact & Contact interface \\
\hline$c y l$ & Cylinder \\
\hline & Maximum elastic limit \\
\hline
\end{tabular}




$\begin{array}{ll}\text { eq } & \text { Equivalent surface } \\ \text { gas } & \text { Gas } \\ \text { jump } & \text { Temperature change across the test interface } \\ m & \text { Mean value } \\ \text { nominal } & \text { Nominal value } \\ p & \text { Minimum plastic limit } \\ \text { real } & \text { Real value } \\ \text { sub } & \text { Substrate } \\ \text { Greek Symbols } & \\ \delta & \text { Deformation } \\ \varepsilon & \text { Tolerance } \\ \theta & \text { Angle of the asperity } \\ v & \text { Poisson's ratio }\end{array}$

\section{INTRODUCTION}

The cooling requirements of the electronics packaging industry continue to become ever more demanding as the trend towards greater compactness and functionality in electronic devices accelerates. Thermal contact resistance along the heat flow path is a pervasive hurdle to effective heat removal in practically all electronics cooling applications. It is also recognized as a critical parameter in the design of avionics and other high-performance thermal management systems [1].

Contact resistance is primarily caused by the imperfect contact between two surfaces due to the presence of microscopic asperities characteristic of engineering surfaces. The real area of contact for such surfaces is only a small fraction (less than 1-2\%) of the nominal contact area even at very high pressures [2]. Even so, most of the heat through the interface flows through the actual contact spots, as the thermal conductivity of these contact spots is much higher than that of the surrounding gas gap. This causes constriction of heat flux lines through the bulk solid material in the vicinity of the contact interface, which leads to a constriction resistance (Figure 1). Contact resistance is the combined effect of constriction resistances at all the contacting asperities on a surface. 
An integrated thermo-mechanical model for the prediction of thermal contact conductance is developed in this work. For given surface profiles and material properties of the two surfaces in contact, and a specified contact pressure, the contact conductance is predicted. The model is validated by comparing against experimental measurements. The variation of contact conductance with surface roughness and material properties is investigated experimentally at the low contact pressures commonly encountered in electronics cooling applications.

\section{EXPERIMENTS}

\subsection{Facility Description}

A steady-state, one-dimensional axial heat flow measurement approach was used to experimentally determine contact conductance values with contributions from gas gap conductance, for a range of contact pressures, interface mean temperatures and heat flow rates, for different metallic materials of different surface roughness [3]. A schematic diagram of the experimental facility is shown in Figure 2(a). The facility consists of a test column, a pneumatic loading system, a load cell, a heating and cooling unit and a vacuum system.

The test column is composed of six cylindrical blocks, each of $2.54 \mathrm{~cm}$ diameter: a copper heat source, two flux meters, two test specimens, and a copper heat sink. The column is centered between the load application mechanism (a pneumatic cylinder) below the column and the load cell above the column as shown in Figure 2(a). A radiation shield is placed around the column to minimize the radial heat losses from the test column. The interfaces between the heat source and flux meter, the heat sink and flux meter, and between the flux meters and the specimens (i.e., at all contacts except that between the test surfaces) are coated with a thermally conductive paste to minimize the contact resistance at these interfaces and maximize the column heat flow.

The heat source and sink elements are identical and the direction of heat flow through the column can be changed without disassembly by generating heat either at the top or bottom of the column, and cooling the other end. For the tests conducted in this work, the heat flow direction was from top to 
bottom. Heat generation is accomplished by means of three $100 \mathrm{~W}$ cartridge heaters embedded in the $6.35 \mathrm{~cm}$-long copper block heat source. Heat is extracted from the column via the heat sink at the bottom of the column. Refrigerated ethylene glycol at $-20^{\circ} \mathrm{C}$ is circulated through a copper coil brazed on the outside of the heat sink to remove heat from the column. The heat source and the heat sink are both insulated with fiberglass insulation.

The facility is equipped with a vacuum system so that tests can be conducted in the absence of an interstitial gas at the test interface, yielding measurements of the solid spot conductance alone. A flexible bellows fit around the bottom of the load column and sealed to the bottom of the base plate complete the column vacuum environment. A rotary vacuum pump is used to evacuate the test chamber. Tests in this work, however, were conducted under atmospheric pressure conditions.

The heat flux is measured using flux meters fabricated from electrolytic iron (Research Material 8420/8421) obtained from the National Institute of Standards and Testing. The thermal conductivity of this material is known to an uncertainty of $3 \%$. Along the $3.81 \mathrm{~cm}$ length of the flux meters, four $0.1 \mathrm{~cm}$ diameter holes are drilled to a depth of $1.27 \mathrm{~cm}$ to reach the axis; each pair of holes is separated by a distance of $0.76 \mathrm{~cm}$. Type $\mathrm{T}$ thermocouples made from 36 AWG special limit thermocouple wire are inserted into these holes and secured with a high conductivity $(k=2.8 \mathrm{~W} / \mathrm{mK})$ epoxy.

The test specimens were fabricated to the same dimensions as the flux meters, with identical placement of thermocouples. One end surface of each test specimen was ground and then roughened to a specified average surface roughness with a dry-media blasting method, using varying sizes of glass beads and aluminum oxide particles. The sample materials tested were aluminum 6061-T6 (UNS A96061), 360 brass (ASTM-B16), 110 copper (ASTM-B152), and stainless steel (AISI-304). Four nominal levels of average surface roughness (ASME95 Centerline Average Surface Roughness), $R_{a}=1,5,10$, and $15 \mu \mathrm{m}$, were considered.

\subsection{Data Reduction}

The experimental determination of thermal contact conductance is illustrated in Figure 2(b) using a schematic of the flow of calculations from the measured centerline temperatures on the left to the 
calculated value of thermal contact resistance (at the interface between samples 1 and 2) on the right. Using a least-squares regression scheme, a linear profile is fit to the axial temperature measurements obtained from the flux meter as a function of axial location. The profile is centered about the vertical center of the component (flux meter or test sample) so that the resulting error is distributed evenly to the extrapolated temperatures of both end surfaces. The extrapolated surface temperature, $T_{a}$, is given by:

$$
T_{a}=x_{a} m+c
$$

The slope, $m$, and intercept, $c$, in this expression are obtained from the measured temperatures at different axial locations:

$$
\begin{gathered}
m=\frac{N \sum_{i=1}^{N} x_{i} T_{i}-\sum_{i=1}^{N} x_{i} \sum_{i=1}^{N} T_{i}}{N \sum_{i=1}^{N}\left(x_{i}^{2}\right)-\left(\sum_{i=1}^{N} x_{i}\right)^{2}} \\
c=\frac{\sum_{i=1}^{N}\left(x_{i}^{2}\right) \sum_{i=1}^{N} T_{i}-\sum_{i=1}^{N} x_{i} \sum_{i=1}^{N}\left(x_{i} T_{i}\right)}{N \sum_{i=1}^{N}\left(x_{i}^{2}\right)-\left(\sum_{i=1}^{N} x_{i}\right)^{2}}
\end{gathered}
$$

The heat flow through the interface is determined as the average of the heat flow through the two flux meters. The contact resistance is then calculated as the ratio of the temperature drop across the interface to the heat flowing through. Thermal contact conductance, $h$, is the reciprocal of the thermal contact resistance:

\subsection{Uncertainty Analysis}

$$
h=\frac{1}{R_{\text {contact }}}=\frac{Q_{\text {avg }}}{T_{d}-T_{e}}
$$

The uncertainty in thermal contact resistance (TCR) can be calculated as [4]:

$$
U_{R_{\text {contact }}}=\left[\left(\frac{U_{T_{d}}^{2}}{\left(T_{d}-T_{e}\right)^{2}}+\frac{U_{T_{e}}^{2}}{\left(T_{d}-T_{e}\right)^{2}}+\frac{U_{Q_{\text {avg }}}^{2}}{Q_{\text {avg }}^{2}}\right) * R_{\text {contact }}^{2}\right]^{1 / 2}
$$

The heat flow through the flux meters, $Q_{1}$ and $Q_{2}$, and their respective uncertainties are given by: 


$$
\begin{gathered}
Q_{i}=-A_{i} k_{i} \frac{T_{m}-T_{n}}{x_{m}-x_{n}} \\
\left.U_{Q_{i}}=\left[\left(\left(\frac{U_{A_{i}}}{A_{i}}\right)^{2}+\left(\frac{U_{k_{i}}}{k_{i}}\right)^{2}+\left(\frac{U_{T_{m}}}{T_{m}-T_{n}}\right)^{2}+\left(\frac{U_{T_{n}}}{T_{m}-T_{n}}\right)^{2}\right]^{2}\right]^{2}\right]^{1 / 2} \\
+\left(\frac{U_{x_{m}}}{x_{m}-x_{n}}\right)^{2}+\left(\frac{U_{x_{n}}}{x_{m}-x_{n}}\right)^{2} \\
i \text { from } 1 \text { to } 2 \\
m=a, n=b \text { for } i=1 \\
m=g, n=h \text { for } i=2
\end{gathered}
$$

The nominal contact surface area of the interface, $A_{i}$ in Equation (6), is based on the test column diameter, $d_{i}\left(A_{i}=\pi d_{i}^{2} / 4\right)$. The uncertainty in the column diameter, $U_{d_{i}}$, is taken as $0.00254 \mathrm{~cm}$ ( $0.1 \%$ of diameter). The corresponding uncertainty in the nominal contact surface area is given by:

$$
U_{A_{i}}=\frac{\pi d_{i} U_{d i}}{2}
$$

The thermal conductivity, $k_{i}$, of the electrolytic iron flux meters is interpolated from the calibration data provided by NIST. The heat flow through the column, $Q_{\text {avg }}$, is taken as the average of the heat flow in the two flux meters, with a corresponding uncertainty:

$$
U_{Q_{\text {avg }}}=\left[\frac{U_{Q_{1}}^{2}+U_{Q_{2}}^{2}}{4}\right]^{1 / 2}
$$

The locations of the end surfaces of the flux meters for the extrapolated temperatures, $x_{m}$ and $x_{n}$, are also required in Equations (6) and (7). The uncertainty in these locations $U_{x_{m}}$ and $U_{x_{n}}$ is taken as $0.0127 \mathrm{~cm}$.

Finally, the uncertainties in the extrapolated surface temperatures for the flux meters and samples are determined. With reference to Equation (1), the uncertainty in $T_{a}$ is given by:

$$
U_{T_{a}}=\left[\left(x_{a} U_{m}\right)^{2}+\left(m U_{x_{a}}\right)^{2}+U_{c}^{2}\right]^{1 / 2}
$$

The uncertainty in the calculated slope, $U_{m}$, and that in the calculated intercept, $U_{c}$, can then be calculated in terms of the random uncertainty for the thermocouple temperature readings (systematic 
uncertainty is taken as zero). Because the thermocouple locations are fixed, the random uncertainty in the axial location is also assumed to be zero, and the systematic uncertainty in the axial location is $0.0127 \mathrm{~cm}$.

The uncertainties in the measurements are summarized in Table 1, and the statistics of heat flow, interface thermal contact resistance and interface temperature are reported in Table 2. The maximum and minimum in each category of Table 2 are the values determined over the entire set of experiments.

The uncertainties in experimental sample dimensions and thermocouple locations had little effect on the overall TCR uncertainty. Instead, the TCR is most strongly influenced by the elemental temperature measurement uncertainty, the amount of heat flowing through the column, and the temperature jump at the test interface. The uncertainty in TCR for the tests presented here ranged from $3 \%$ to $70 \%$ of the calculated TCR value, with an average uncertainty of $15 \%(0.033 \mathrm{~K} / \mathrm{W})$ and a median uncertainty of $10 \%$. As TCR decreases, the temperature jump across the test interface decreases for a given constant column heat flux, but the elemental uncertainty in the temperature measurements remains constant, causing an increase in TCR uncertainty. A second category of cases with larger uncertainties resulted from low column heat flows imposed to keep the mean interface temperature close to $30^{\circ} \mathrm{C}$ (chosen as the approximate interface set temperature for all measurements). The uncertainty would decrease significantly if the chiller set temperature were reduced and the column heat flux were increased, with the interface temperature still maintained at $30^{\circ} \mathrm{C}$.

The average heat loss from the column between flux meter 1 and flux meter 2 is $2.7 \%$ of the calculated average column heat flow, and the median value of this loss is $1.5 \%$ of the calculated average column heat flow.

\section{NUMERICAL PREDICTION METHODOLOGY}

As already described, heat flow through an imperfect contact occurs mainly through the actual contact spots between the highest asperities of the two surfaces. As the contact pressure is increased, deformation of the contacting asperities increases, and additional asperities may also come into contact. This leads to an increase in the real area of contact, which in turn causes a decrease in constriction of heat 
flux lines and an increase in contact conductance. Prediction of contact conductance involves determining the real area of contact for all the contact spots and determining the heat flow through each contact spot. Hence the problem of determining the contact conductance can be divided into two parts, which can be considered sequentially:

i. Finding the real area of contact for all the contact spots, for a given contact pressure, by considering the deformation of each individual asperity, and,

ii. Finding the constriction resistance values, given the dimensions of each contact spot, by considering the constriction of heat flux lines through the actual contact spot.

Models for surface deformation and constriction resistance are developed in the following to carry out these calculations. Input parameters to the surface deformation model are provided by a surface topography analysis.

A number of different models have been presented in the literature for prediction of thermal contact conductance [5-10]. A discussion of these models, their shortcomings and the need for a more robust and comprehensive model are available elsewhere [11,12].

\subsection{Surface Deformation Analysis}

The surface deformation analysis considers contact of an elastic-plastic sphere of a given radius and material properties with a rigid flat half-plane. The solution is then extended to the problem of contact between two rough surfaces. Consider the contact of an elastic-plastic sphere of radius $R$ with a perfectly hard, smooth half-plane. If the sphere is pressed into the half-plane with a mean pressure $p_{m}$ such that the deformation of the sphere is given by $\delta$ and the area of contact by $\pi a^{2}$ (where $a$ is the radius of contact) then $\delta, p_{m}$ and $a$ can be related for the different deformation modes of the sphere as described below.

For elastic deformation the mean contact pressure of an elastic-plastic sphere in contact with a rigid half-plane can be calculated by using Hertz theory of elastic contact [13]:

$$
p_{m}=\frac{4 E^{*}}{3 \pi}\left(\frac{\delta}{R}\right)^{\frac{1}{2}}
$$


in which $E^{*}$ is the effective elastic modulus of the contact surfaces and is given by,

$$
\frac{1}{E^{*}}=\frac{1-v_{1}^{2}}{E_{1}}+\frac{1-v_{2}^{2}}{E_{2}}
$$

Here, $E_{1}, E_{2}$ and $v_{1}, v_{2}$ are the elastic moduli and Poisson's ratios of the two contacting surfaces. The contact radius for elastic deformation is calculated using Sneddon's formula [14]:

$$
\delta=\frac{1}{2} a \ln \left(\frac{R+a}{R-a}\right)
$$

For a compressible material, mean contact pressure for elastic-plastic deformation can be calculated using Johnson's expanding cavity model [13] and [15]:

$$
\frac{p_{m}}{Y}=\frac{2}{3}\left[2+\ln \left(\frac{\left(E^{*} / Y\right) * a / R+4 *(1-2 v)}{6 *(1-v)}\right)\right]
$$

in which $Y$ is yield stress of the material. Since no analytical models are available for area of contact for the elastic-plastic region, a finite element model (FEM) has been developed. A static deformation analysis for contact of an elastic-plastic sphere with a smooth rigid half-plane was conducted using the commercial FEM package ABAQUS/Standard [16]. The results of the finite element analysis are shown in Figure 3. The contact area, $A=\pi a^{2}$, is plotted as a function of deformation $\delta$ in Figure 3(a), while the non-dimensional contact area $A /(\delta R)$ is plotted against non-dimensional deformation $(\delta / R) /(Y / E)^{2}$ in Figure 3(b). A power-law approximation to the results in Figure 3(b) used in the present work is given by

$$
\frac{A}{\delta R}=2.448\left(\frac{\delta / R}{(Y / E)^{2}}\right)^{0.1265}
$$

For plastic deformation, the mean contact pressure can be calculated using the relationship due to Tabor [17]:

$$
\frac{p_{m}}{Y}=3
$$

Assuming no piling-up or sinking-in, the area of contact for plastic deformation can be expressed using the following simple relation [13]: 


$$
a^{2}=2 \delta R
$$

Finally, the maximum elastic and minimum plastic deformation limits are determined. The maximum elastic deformation limit $\delta_{e}$ represents the boundary between elastic and elastic-plastic deformation modes and is calculated using von Mises' shear strain-energy criterion [13]:

$$
\delta_{e}=\left(\frac{\pi}{2}\left(\frac{-3}{2\left(1+t^{2}\right)}+(1+v)\left(1-t \tan ^{-1}\left(\frac{1}{t}\right)\right)\right)^{-1}\right)^{2} \frac{Y^{2} R}{E^{*^{2}}}
$$

in which $t$ can be calculated by solving the following equation numerically for a given value of $v$.

$$
t=\left(\tan \left[\frac{3 t+(1+v) t\left(1+t^{2}\right)}{(1+v)\left(1+t^{2}\right)^{2}}\right]\right)^{-1}
$$

Similarly, the minimum plastic deformation limit $\delta_{p}$ represents the boundary between the elastic-plastic and plastic modes of deformation and is calculated using the expanding cavity model [13]:

$$
\delta_{p}=(48.86-46.03 v)^{2} \frac{Y^{2} R}{E^{*^{2}}}
$$

A detailed discussion of deformation limits and the derivation of the above equations is available in [11].

The relationship between mean pressure and contact radius from the surface deformation model obtained by combining the above set of equations is illustrated in Figure 4.

\subsection{Constriction Resistance Analysis}

The constriction resistance for a single asperity modeled as a semi-infinite cylinder terminating in the frustum of a cone was analyzed as shown in Figure 5. This geometry best represents individual deforming asperities [18]. A steady-state heat transfer analysis was performed with a finite-volume approach using the commercial CFD software FLUENT [19]. A wide range of parameters were considered in the analysis, including the ratio of the contact spot radius to the cylinder radius $(a / b)$, the contact angle of the asperity $(\theta)$, and the ratio of the conductivity of the gas gap (usually air) to the 
conductivity of the substrate material $\left(k_{\text {gas }} / k_{\text {sub }}\right)$. Using a nonlinear least-squares regression analysis, constriction resistance was correlated as a function of $\theta, a / b$, and $k_{g a s} / k_{s u b}$ as:

$$
R_{\text {cons }-c y l}=\frac{1.608}{4 k_{\text {sub }} a}\left\{\left(1-\frac{a}{b}\right)^{\left[2.565(\kappa)^{0.141} \theta^{0.272}\right]}\right\}\left\{\boldsymbol{\theta}^{\left[0.244(1-a / b)^{2.792}(\kappa)^{-0.612}\right]}\right\}\left\{\kappa^{\left[0.677(1-a / b)^{82.1} \theta^{-0.433}\right]}\right\}
$$

The conductivity ratio used in this correlation is given by $\square \kappa=k_{\text {sub }} /\left(k_{\text {sub }}+1000 k_{\text {gas }}\right)$. The effect of gas conductivity is captured using the parameter $\kappa$ in preference to the ratio $k_{\text {gas }} / k_{\text {sub }}$. If $k_{\text {gas }} / k_{\text {sub }}$ were used as one of the factors in the correlation for $R_{\text {cons-cyl, }}$ the constriction resistance would take a nonphysical value of zero for the case of a vacuum (i.e., for $k_{\text {gas }}=0$ ). Because $k_{\text {sub }}$ is in general three to four orders of magnitude higher than $k_{g a s}$, the factor of 1000 ensures that changes in $k_{\text {gas }}$ are appropriately reflected in $\kappa$. This correlating equation is valid for the following ranges of parameter values: $0.01<a / b$ $<0.1 ; 5.83 \times 10^{-5}<k_{\text {gas }} / k_{\text {sub }}<1.61 \times 10^{-3}$; and $0.0175<\theta<0.628$. Details of the constriction resistance analysis are available in $[18,20]$.

\subsection{Surface Topography Analysis}

The topography of the contacting surfaces of the cylindrical test samples (aluminum, brass, copper and stainless steel) was analyzed. Six 2-D scans were obtained on each surface (three parallel scans each in two orthogonal directions) using a diamond-tip stylus surface scanning instrument (Surfanalyzer 5400) for a total of 12 surface scans for the contacting surface pair. The data obtained from these scans include the height of the surface profile above or below the centerline, at equidistant points along a straight line of given length (generally $20 \mathrm{~mm}$ for the present work). Each pair of scans, one from each surface, is converted to an equivalent profile as follows. A linear least-squares fit of the profile data is used to remove any slope in the data that may have been introduced from the surface scanner being out of level. The linear fit is also used to adjust the profile data to have a mean profile height of zero, centering the data about the zero ordinate. The profile heights at corresponding points on both surfaces are then summed to form one equivalent profile scan. These equivalent profiles are used to find the total number of asperities on each surface as well as their peak heights and radii of curvature. 
The radii of curvature and peak density in a surface profile are dependent on the sampling interval of the scanning instrument [21]. As the sampling interval for a given instrument decreases, more details of the surface are captured. Hence increasingly smaller asperities are identified, which may not be important to the deformation analysis. The average radius of curvature of these asperities decreases with decreasing sampling interval while the asperity density increases. Hence the profile of the surface used to determine the contact conductance is not unique, but is instead dependent on the resolution of the scanning instrument used. In order to overcome this dependence, the surface profile data were filtered to remove short-wavelength asperities. This was achieved using a first-order Butterworth filter to filter the equivalent profiles through a low-pass cutoff wavelength prescribed by Black and Garimella [22]. These filtered equivalent 2-D surface profiles were used to calculate an equivalent 3-D rough surface [11]. This equivalent 3-D surface profile was used for prediction of contact conductance in the present work.

\subsection{Prediction Methodology}

Greenwood and Tripp [23] showed that the contact of two rough surfaces could be modeled as the contact of a smooth surface with an equivalent rough surface. Since the real area of contact is only a small fraction, generally less than 1-2\% [2], of the nominal contact area even at high contact pressures, the interaction between surrounding asperities may be neglected. Each asperity may thus be considered as a deforming sphere in contact with a smooth half-space. The problem is thus reduced to the contact of a surface characterized by randomly distributed, mutually independent, spherical asperities with a smooth, hard surface. Hence the surface deformation analysis presented above can be used to calculate the contact area and mean contact pressure of the two rough surfaces for a given deformation of the asperities.

The prediction methodology for calculation of contact conductance is as follows [12]. The separation $d$, between the smooth surface and the mean plane of the equivalent rough surface, is assumed. This is used to calculate the deformation of the asperities on the equivalent rough surface as $\delta_{i}=l_{i}-\left(z_{e q}+d\right)$, where $\delta_{i}$ is the deformation of an asperity of height $l_{i}$ and $z_{e q}$ is the height of the mean plane of the equivalent rough surface. The maximum elastic $\left(\delta_{e}\right)$ and minimum plastic $\left(\delta_{p}\right)$ deformation limits of each asperity are calculated, and are compared to the deformation of individual asperities to 
determine their deformation modes. The equations corresponding to these deformation modes are used to calculate the mean contact pressure $p_{m i}$, contact radius $a_{i}$ and contact area $A_{i}$ for all the contacting asperities. The total contact force is then calculated as $\sum p_{m i} A_{i}$ and compared to the applied load. If the calculated and applied loads do not match within a given tolerance, a new value of the separation distance $d$ is assumed and the process is repeated.

When the contact force matches the applied load, the angle of contact $\theta_{i}$, of each contacting asperity with the smooth surface is calculated as $\theta_{i}=(180 / \pi) \cos ^{-1}\left(\left(R_{i}-\delta_{i}\right) / R_{i}\right)$, where $R_{i}$ is the radius of curvature of the asperity. The angle of contact of each asperity, together with $\left(A_{\text {real }} / A_{\text {apparent }}\right)^{1 / 2}$ and $k_{\text {gas }} / k_{\text {sub }}$, are used to calculate the constriction resistance for that particular asperity using Eq. (22). In calculating constriction resistance of an asperity, the asperities in contact are assumed to be uniformly distributed across the apparent area of contact such that $\left(A_{\text {real }} / A_{\text {apparent }}\right)^{1 / 2}=a / b$, where $A_{\text {real }}$ and $A_{\text {apparent }}$ are the total real and apparent areas of contact. This process is repeated for all the contacting asperities and individual solid spot conductance values calculated using $h_{i}=1 / 2 R_{i}$ are added to obtain the total contact conductance for the interface.

\section{RESULTS}

\subsection{Experimental Results for Contact of Similar Materials}

The effects of loading and unloading cycles, surface roughness and material properties on thermal contact conductance (TCC) are presented in the following. The experimental results were compared to published values in [24]. Although the exact conditions from the present study of surface roughness, material properties, and gas gap conductance were not matched in [24], the experimental results were seen to agree with the available published data for comparable conditions. In fact, the primary reason for performing experiments in this study was to obtain results on samples for which all input parameters required in the model developed were available, such that the model predictions could be validated. 


\subsubsection{Effect of Loading-Unloading Cycles}

As the interface between two rough surfaces is subjected to loading-unloading cycles, an increase in thermal contact conductance is observed for the second and subsequent loadings compared to the first loading, mainly due to the progressive nature of the deformation of asperities on the surfaces in contact. This dependence on loading-unloading cycles, also documented in $[25,26]$, can be seen in the TCC results for a representative test considered in Figure 6(a). Results for contact between two nominally flat aluminum 6061-T6 surfaces with $0.5 \mu \mathrm{m}$ average surface roughness are presented, with TCC data recorded for several loading and unloading cycles. An increase in thermal contact conductance is observed for successive loadings, but only during the first few cycles. After the second loading cycle, the TCC comes to a steady value with respect to loading cycle. This behavior was observed for all the

experiments performed. For all the remaining results reported in this work, the samples were subjected to repeated loading and unloading until the thermal contact conductance values became invariant with respect to loading cycle.

\subsubsection{Effect of Surface Roughness}

As expected, thermal contact conductance was found to decrease as surface roughness increased. As the surface roughness increases, the number of contact spots and the real area of contact decreases, thus allowing for less solid spot conductance across the interface. This trend was exhibited for all the bare contacts tested between similar material sample pairs; results for stainless steel surfaces are presented in Figure 6(b). The TCC is seen to decrease with increasing surface roughness with a 93\% drop at the maximum interface pressure for an increase in the nominal surface roughness from $1 \mu \mathrm{m}$ to $15 \mu \mathrm{m}$ $\left(\mathrm{R}_{\mathrm{a}}\right)$. For similar contact pressures, the percentage variation in TCC with surface roughness decreases as the surface roughness increases.

\subsubsection{Effect of Material Properties}

Material properties of the two surfaces in contact have a significant effect on the observed TCC. Properties for the metals considered in this work are shown in Table 3 [27]. Results for bare contact between the four different pairs of sample materials are shown in Figure 6(c) for a surface roughness of 5 
$\mu \mathrm{m} \mathrm{R}_{\mathrm{a}}$. The TCC values in the figure are seen to scale with the material thermal conductivity. While the significant expected influence of thermal conductivity on TCC is obvious from the figure, the effects of material properties such as micro-hardness and yield strength are less easily discerned. The effect of yield strength can be observed by comparing the contact conductance values for aluminum-aluminum and brass-brass contacts in Figure 6(c) at low loads. Although aluminum has a much higher conductivity, aluminum and brass contacts have similar TCC values for pressures in the region of 0.5 to $1.5 \mathrm{MPa}$. This indicates that a higher yield strength leads to a reduction in TCC. The higher yield strength of aluminum means that geometrically equivalent asperities on brass begin to deform plastically before those on aluminum. This results in a greater contact area for brass at a given load, increasing the contact conductance to the same value as for aluminum, even though aluminum has a higher thermal conductivity. However, as the yield strength of aluminum is reached at higher loads, the contact area for aluminum contact begins to increase due to plastic deformation, leading to a more rapid increase in TCC for the higher-conductivity aluminum.

\subsubsection{Effect of Interface Pressure}

As can be seen from the results in Figure 6, TCC increases with increasing interface pressure, as is well established. As the contact pressure at the interface is increased, the contacting asperities deform further in addition to new asperities coming into contact, which increases the amount of actual contact area. The solid spot contribution to thermal contact conductance correspondingly increases.

\subsection{Experimental Results for Contact of Dissimilar Materials}

Thermal contact conductance measurements were also obtained for contact between dissimilar metallic surfaces. Results are presented in Figure 7(a) for contact of aluminum and stainless steel. Two different surface roughness values, $1 \mu \mathrm{m}$ and $14 \mu \mathrm{m} \mathrm{R}_{\mathrm{a}}$ are considered for both materials. The results indicate that stainless steel acts as the controlling resistance for the contact, and TCC scales largely on the surface roughness of the stainless steel samples. Thus the $1 \mu \mathrm{m} \mathrm{R}_{\mathrm{a}}$ stainless steel surface produces the higher conductance values; of the two sets of these results, the contact pair with the less rough aluminum 
surface yields the higher conductance. The TCC results for the $14 \mu \mathrm{m}$ stainless steel surface in contact with both the $1 \mu \mathrm{m}$ and $14 \mu \mathrm{m}$ aluminum surfaces lie lower, and are closely grouped.

Figure 7(b) shows a comparison of similar versus dissimilar material contact. Results for contact between $1 \mu \mathrm{m} \mathrm{R}_{\mathrm{a}}$ aluminum and $1 \mu \mathrm{m} \mathrm{R}_{\mathrm{a}}$ stainless steel interfaces are compared to those for bare contact between similar materials of the same surface roughness. As may be expected, the TCC results for the dissimilar material pair lie between the results for the aluminum-aluminum and stainless-stainless TCC values.

\subsection{Experimental Validation of Numerical Predictions}

Contact conductance values predicted from the model developed in this work are compared to experimental results for $1 \mu \mathrm{m} \mathrm{Al} / \mathrm{Al}$ contact in Figure 8 . The measured values are shown along with predictions using the unfiltered surface profiles, as well as those with filtered profiles. The pre- and postload predictions refer to the use of surface profiles obtained before and after the contact tests, respectively. It is clear that predictions using unfiltered scans are not in agreement with experiment. The filtered pre-load and post-load predictions follow the same trend, with the pre-load predictions being the higher of the two. The predictions of TCC for the $1 \mu \mathrm{m} \mathrm{Al} / \mathrm{Al}$ contact agree very well with the experimental measurements, exhibiting an average deviation from the experiment of $2 \%$. It may be noted that filtering causes the predicted contact conductance to increase somewhat non-monotonically with load, as can be observed from the predictions in Figure 8. The trend line shown through the predictions is obtained as a least-squares fit. Similar comparisons for three other surface pairs are shown in Figures 9 through 11. These figures show that predictions for the $15 \mu \mathrm{m} \mathrm{Al} / \mathrm{Al}$ contact have an average deviation of $26 \%$ from experiment with most of the variation occurring in the range of 3-5 MPa. Corresponding deviations for $5 \mu \mathrm{m}$ brass-brass contact is $17 \%$, and for $5 \mu \mathrm{m}$ copper-copper surface is $11 \%$. While the predictions do not exactly match the experimental values in all cases (such as for the $5 \mu \mathrm{m}$ copper and 15 $\mu \mathrm{m}$ aluminum cases, where the experiments drop off more rapidly than the predictions), the comparisons to experimental data are good in most cases. The deviations are due to the filtering method applied to the 
profile data and is discussed further in the following. Care should be taken in using the model for high pressures (> $3 \mathrm{MPa}$ ) on surfaces with large roughness.

The larger variations in predicted values with some of the surfaces are chiefly due to the error in the correlation used to determine the low-wavelength cutoff and the manner in which the surfaces are characterized and filtered [22], as described in section 3.3. While filtering out of smaller wavelengths is necessary in order to retain only the wavelengths that are important to the physics of deformation of microscopic asperities, it also has the disadvantage of affecting the surface peak heights. The extent of this effect is shown in Figure 12, where the height of the large asperity on the right decreases as the cutoff wavelength increases. Filtering has another significant effect on the surface profile. As the surface is filtered with increasing values of cutoff wavelength, the two asperities shown in Figure 12 (two smaller asperities on the left) begin to merge into one asperity. Just before they merge, their radii of curvature increase at least tenfold. This substantial increase in the radius of curvature causes the mean plane separation at that particular load to increase substantially, reducing the predicted area of contact and hence the contact conductance. After these asperities merge, the radius of curvature returns to a more reasonable value, resulting once again in more accurate predictions of the contact conductance. Ideally, the filtering should remove the undesired surface wavelengths while more or less maintaining the peak heights.

Some of the crucial inputs and limitations of the prediction scheme developed in this work, which can affect its ability to correctly predict contact conductance, are as follows: (i) The prediction method developed requires complete 3-D profiles of the contacting surfaces, which are often not available, or can be difficult to obtain. Hence, 2-D profiles were extrapolated to obtain 3-D profiles. The six 2-D profiles used for each surface may have been too small a number to accurately capture the 3-D surface profile. (ii) The prediction scheme requires the surface microhardness of both the surfaces in contact. As increasingly rough surfaces are considered, the measurement of surface microhardness becomes more uncertain due to limitations involved with the indentation measurement technique. Hence the microhardness values input into the prediction scheme suffer from some uncertainty, affecting the predictions. (iii) In the present stage of the modeling effort, only the effect of the roughness of the surface profiles is captured, and the 
surface is assumed nominally flat. Wavy, concave, or convex surface profiles (macroscopic features) are not considered. (iv) The filtering scheme smooths the profiles, decreasing the asperity heights and increasing the radius of curvature. However, the filtering method does to some extent account for the fact that at high contact pressures, deformation of many of the contacting asperities can be so large that some of the adjacent asperities start behaving as a single asperity. This leads to a variation in the heat flow versus contact area characteristics of such asperities, and in turn, a change in the rate of increase in contact conductance with interface pressure (because contact conductance is proportional to $a$ whereas contact force is proportional to $a^{2}$ ); such an effect is discernible in the plots of experimental TCC values presented as a function of interface pressure, specifically, in Figure 11 where the experimental values of contact conductance show a more rapid decrease in slope than the predicted values in the 4-5 MPa range.

\section{CONCLUSIONS}

A numerical model has been developed for the prediction of thermal contact conductance at metal-metal contact interfaces. Using the model, it is shown that contact conductance can be predicted from a knowledge merely of the surface topography and material properties of the two contacting surfaces for a given contact pressure and apparent area of contact. The predictive approach incorporates a surface deformation model, which is shown to match experimental results from the literature very well. In parallel, an experimental facility has been constructed to measure thermal contact conductance across an interface, especially at the low pressures encountered in electronics cooling applications, with the primary purpose of validating the model developed. The effects on contact conductance of variations in interface pressure, surface finish, and types of materials were studied. Predicted results for contact conductance from the present model show satisfactory agreement with the experimentally determined values. 


\section{Acknowledgements}

Support for this work from members of the Cooling Technologies Research Center, a NSF Industry/University Cooperative Research Center (www.ecn.purdue.edu/CTRC), is gratefully acknowledged.

\section{REFERENCES}

[1] Madhusudana, C.V., 1996, Thermal Contact Conductance, Springer-Verlag, New York.

[2] Bowden, F.P. and Tabor, D., 1950, The Friction and Lubrication of Solids, Oxford University Press, London.

[3] Litke, P.J., 2002, Experimental Determination of Thermal Contact Conductance, M. S. Thesis, Purdue University, West Lafayette, Indiana.

[4] Coleman, H.W. and Steele, W.G., 1999, Experimentation and Uncertainty Analysis for Engineers, John Wiley and Sons, New York.

[5] Greenwood, J. A. and Williamson, J. B. P., 1966, "Contact of nominally flat surfaces," Proceedings of the Royal Society of London, Series A, 295, pp. 300-319.

[6] Cooper, M. G., Mikic, B. B. and Yovanovich, M. M., 1969, “Thermal contact conductance,” International Journal of Heat and Mass Transfer, 12, pp. 279-300.

[7] Mikic, B. B., 1974, “Thermal contact conductance: Theoretical considerations," International Journal of Heat and Mass Transfer, 17, pp. 205-214.

[8] Majumdar, A. and Tien, C.L., 1991, "Fractal network model for contact conductance," Journal of Heat Transfer, 113, pp. 516-525.

[9] Sridhar, M.R. and Yovanovich, M.M., 1996, "Elastoplastic contact conductance model for isotropic, conforming rough surfaces and comparison with experiments," Journal of Heat Transfer, 118, pp.3-9.

[10] Li, Y.Z., Madhusudana, C.V. and Leonardi, E., 1998, "Experimental investigation of thermal contact conductance: Variations of surface microhardness and roughness," International Journal of Thermophysics, 19, pp. 1691-1704.

[11] Singhal, V., 2001, Prediction of Thermal Contact Conductance by Integrated Thermal and Surface Deformation Analysis, M. S. Thesis, Purdue University, West Lafayette, Indiana. 
[12] Singhal, V. and Garimella, S.V., 2001, "Prediction of thermal contact conductance by surface deformation analysis," Proceedings of International Mechanical Engineering Congress and Exposition, New York, IMECE2001/HTD-24376.

[13] Johnson, K.L., 1985, Contact mechanics, Cambridge University Press, Cambridge.

[14] Sneddon, I.N., 1965, "The relation between load and penetration in the axisymmetric Boussinesq problem for a punch of arbitrary profile," International Journal of Engineering Science, 3, pp. 46-57.

[15] Fischer-Cripps, A.C., 2000, Introduction to Contact Mechanics, Springer-Verlag, New York.

[16] Hibbitt, Karlsson and Sorenson, Inc., 1998, ABAQUS Theory Manual, Version 5.8, Pawtucket, Rhode Island.

[17] Tabor, D., 1951, The Hardness of Metals, Oxford University Press, Oxford.

[18] Olsen, E.L., Garimella, S.V. and Madhusudana, C.V., 2002, "Modeling of constriction resistance in coated joints," AIAA Journal of Thermophysics and Heat Transfer, 16, pp. 207-216.

[19] Fluent Inc., 2000, Fluent 6.0 User's Guide, Lebanon, New Hampshire.

[20] Black, A.F., Singhal, V. and Garimella, S.V., 2004, "Analysis and prediction of constriction resistance for contact between rough engineering surfaces," AIAA Journal of Thermophysics and Heat Transfer, 18, pp. 30-36.

[21] Ju, Y. and Farris, T.N., 1996, "Spectral analysis of two-dimensional contact problems," Journal of Tribology, 118, pp. 320-328.

[22] Black, A.F. and Garimella, S.V., "Characterization of rough engineering surfaces for use in thermal contact conductance modeling," AIAA Journal of Thermophysics and Heat Transfer (in review).

[23] Greenwood, J.A. and Tripp, J.H., 1970-71, "The contact of two nominally flat rough surfaces," Proceedings of the Institution of Mechanical Engineers, 185, pp. 625-633.

[24] Heat Transfer and Fluid Flow DataBbooks, General Electric Company, Research and Development Center, Schenectady, N.Y., 1970.

[25] Williamson, M. and Majumdar, A., 1992, "Effect of surface deformation on contact conductance," Journal of Heat Transfer, 114, pp. 802-810.

[26] Li, Y.Z., Madhusudana, C.V. and Leonardi, E., 2000, "On the enhancement of the thermal contact conductance: Effect of loading history," Journal of Heat Transfer, 122, pp. 46-49.

[27] Norton, R.L., 1998, Machine Design: An Integrated Approach, $3^{\text {rd }}$ ed., Prentice-Hall, New Jersey. 


\section{LIST OF TABLES}

Table 1. Measurement uncertainties.

Table 2. Statistical analysis of experimental variables.

Table 3. Material properties of test samples [27].

\section{LIST OF FIGURES}

Figure 1. Constriction of heat flow lines through a joint.

Figure 2. (a) Thermal Contact Conductance Facility; (b) Graphical representation of the data analysis procedure.

Figure 3. Results of the finite element analysis: (a) Variation of contact area with deformation and, (b)

Variation of non-dimensional contact area $\frac{A}{\delta R}$ with non-dimensional deformation $\frac{\delta / R}{(Y / E)^{2}}$ in the

elastic-plastic region.

Figure 4. Comparison of the present surface deformation model with the earlier model of Li et al. [10] and experimental results [13].

Figure 5. Semi-infinite cylinder terminating in the frustum of a cone.

Figure 6. (a) Effect of loading-unloading cycles on TCC between two nominally flat $0.5 \mu \mathrm{m} \mathrm{Ra}$ aluminum 6061-T6 samples; (b) TCC for stainless steel-to-stainless steel bare contact with varying surface roughness; (c) TCC for bare contact between $5 \mu \mathrm{m}$ Ra surfaces for tests between similar materials Figure 7. Thermal contact conductance for aluminum-to-stainless steel contact with an Ra of (a) $1 \mu \mathrm{m}$ and $14 \mu \mathrm{m}$ and, (b) $1 \mu \mathrm{m}$ for both surfaces.

Figure 8. Comparison of experimental and predicted TCC values for aluminum-aluminum bare contact with $1 \mu \mathrm{m}$ Ra.

Figure 9. Comparison of experimental and predicted (with scans taken before and after loading) TCC values for aluminum-aluminum bare contact with $15 \mu \mathrm{m} \mathrm{Ra}$

Figure 10. Comparison of experimental and predicted TCC values for brass-brass bare contact with $5 \mu \mathrm{m}$ Ra.

Figure 11. Comparison of experimental and predicted TCC values for copper-copper bare contact with 5 $\mu \mathrm{m}$ Ra.

Figure 12. Variation in profile heights and radii of curvature due to filtering the profile data. 
Table 1. Measurement uncertainties.

\begin{tabular}{|c|c|c|c|c|c|}
\hline Variable & Temperature & $\begin{array}{c}\text { Column } \\
\text { Diameter }\end{array}$ & $\begin{array}{c}\text { Axial } \\
\text { Thermocouple } \\
\text { Location }\end{array}$ & $\begin{array}{c}\text { Electrolytic } \\
\text { Iron Thermal } \\
\text { Conductivity }\end{array}$ & $\begin{array}{c}\text { Column } \\
\text { Axial Load }\end{array}$ \\
\hline Uncertainty & $0.2 \mathrm{~K}$ & $0.00254 \mathrm{~cm}$ & $0.0127 \mathrm{~cm}$ & $3 \%$ & $0.9 \mathrm{kPa}$ \\
\hline
\end{tabular}

Table 2. Statistical analysis of experimental variables.

\begin{tabular}{|c|c|c|c|c|c|c|c|c|c|c|}
\hline & \multirow{2}{*}{$\begin{array}{l}Q_{1} \\
{[W]}\end{array}$} & \multirow{2}{*}{$\begin{array}{c}\mathrm{U}_{\mathrm{Q} 1} \\
{[\mathrm{~W}]}\end{array}$} & \multirow{2}{*}{$\begin{array}{l}Q_{2} \\
{[W]}\end{array}$} & \multirow{2}{*}{$\begin{array}{c}\mathrm{U}_{\mathrm{Q} 2} \\
{[\mathrm{~W}]}\end{array}$} & \multirow{2}{*}{$\begin{array}{l}\Delta \mathrm{Q} \\
{[\mathrm{W}]}\end{array}$} & \multirow{2}{*}{$\begin{array}{l}\mathrm{R}_{\text {contact }} \\
{[\mathrm{K} / \mathrm{W}]}\end{array}$} & \multicolumn{2}{|c|}{$U_{\text {Rcontact }}$} & \multirow{2}{*}{$\begin{array}{c}\mathrm{T}_{\text {interface }} \\
{\left[{ }^{\circ} \mathrm{C}\right]}\end{array}$} & \multirow{2}{*}{$\begin{array}{c}\Delta \mathrm{T} \\
{\left[{ }^{\circ} \mathrm{C}\right]}\end{array}$} \\
\hline & & & & & & & {$[\mathrm{K} / \mathrm{W}]$} & [\%] & & \\
\hline Maximum & 27.147 & 0.917 & 27.741 & 0.941 & 1.656 & 3.081 & 0.151 & $70.33 \%$ & 33.84 & 28.28 \\
\hline Minimum & 6.459 & 0.390 & 6.347 & 0.419 & -0.616 & 0.026 & 0.013 & $3.19 \%$ & 26.32 & 0.57 \\
\hline Average & 18.923 & 0.693 & 18.840 & 0.707 & 0.082 & 0.456 & 0.033 & $15.05 \%$ & 28.67 & 6.51 \\
\hline Median & 20.706 & 0.731 & 20.913 & 0.749 & -0.192 & 0.190 & 0.019 & $9.74 \%$ & 29.21 & 3.82 \\
\hline
\end{tabular}

Table 3. Material properties of test samples [27].

\begin{tabular}{|c|c|c|c|c|}
\hline Material & $\begin{array}{c}\text { Thermal } \\
\text { Conductivity } \\
{[\mathrm{W} / \mathrm{mK}]}\end{array}$ & $\begin{array}{c}\text { Yield Strength } \\
{[\mathrm{MPa}]}\end{array}$ & $\begin{array}{c}\text { Young's } \\
\text { Modulus of } \\
\text { Elasticity } \\
{[\mathrm{GPa}]}\end{array}$ & $\begin{array}{c}\text { Poisson's Ratio, } \\
v\end{array}$ \\
\hline Aluminum & 190 & 353 & 69 & 0.33 \\
\hline Brass & 99 & 166 & 97 & 0.34 \\
\hline Copper & 396 & 193 & 110 & 0.34 \\
\hline Stainless Steel & 17 & 380 & 200 & 0.30 \\
\hline
\end{tabular}




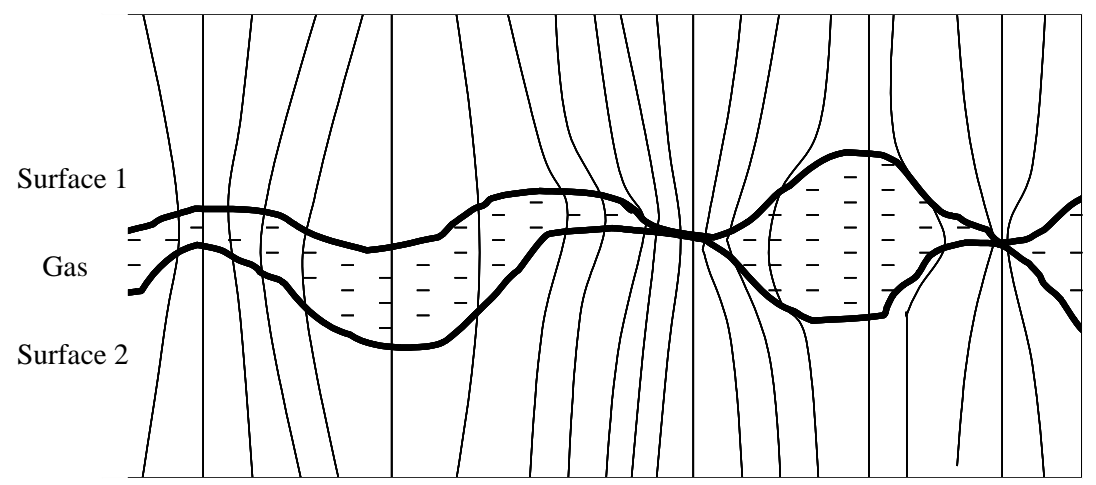

Figure 1. Constriction of heat flow lines through a joint. 


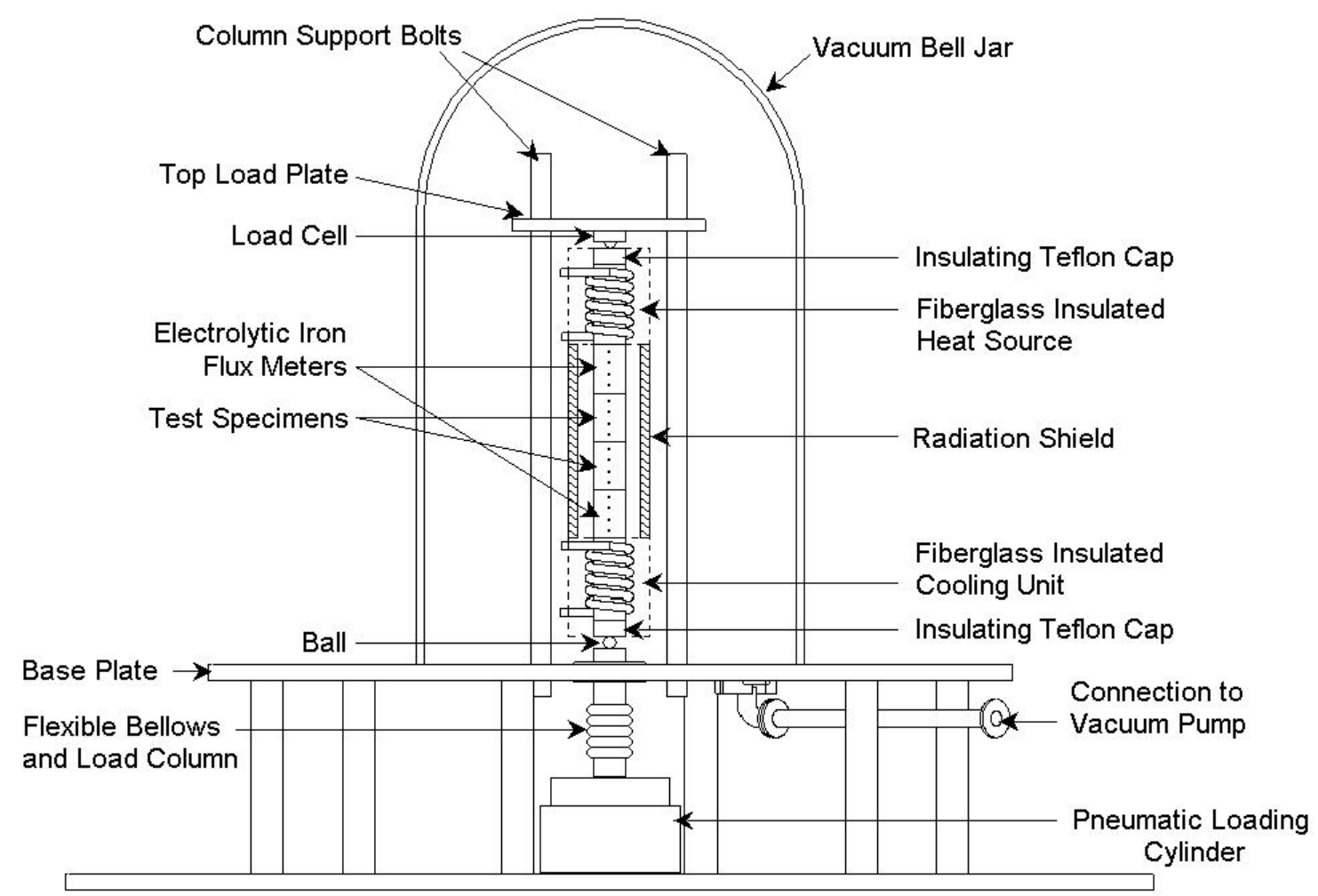

(a)

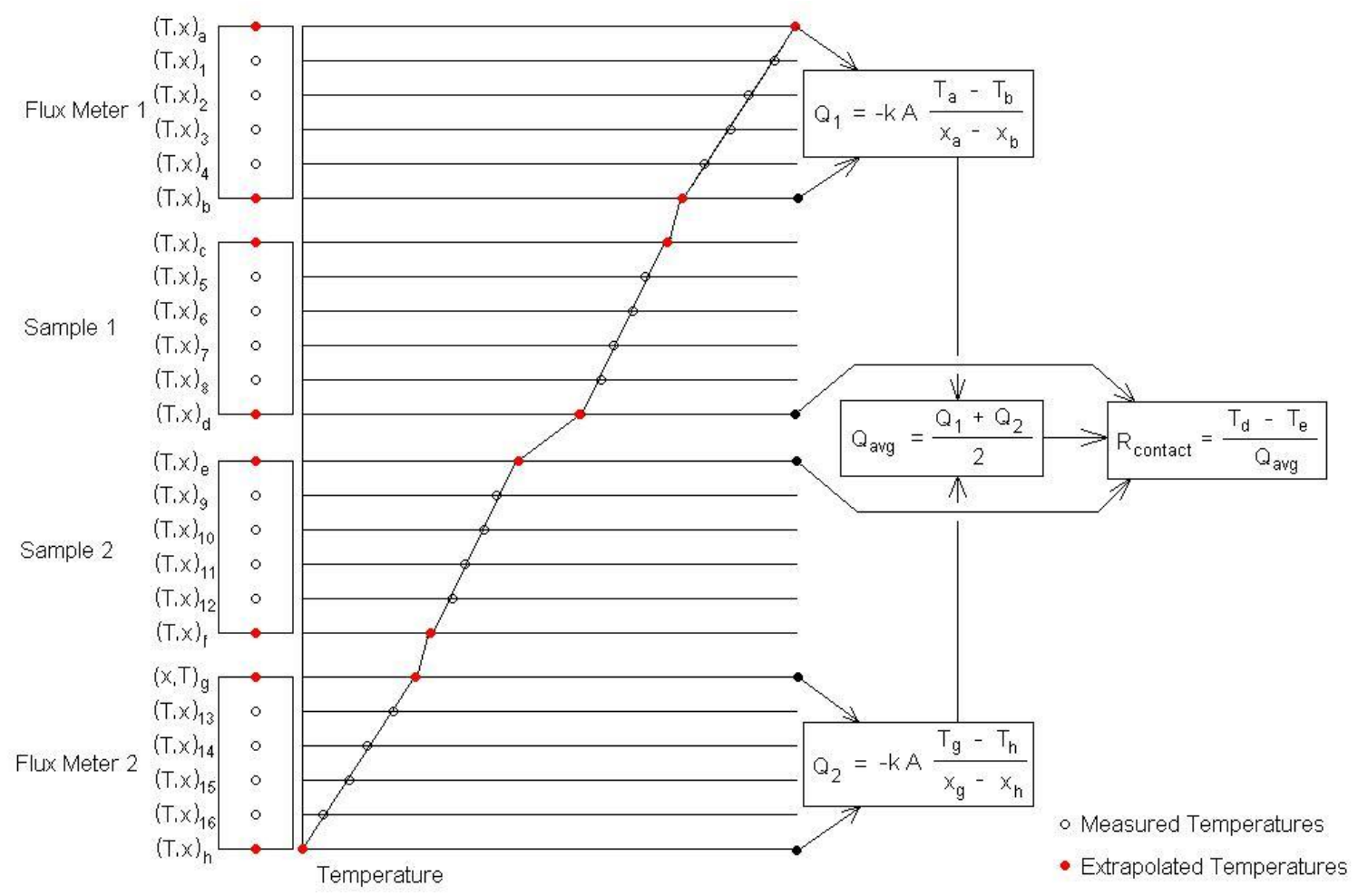

(b)

Figure 2. (a) Thermal Contact Conductance Facility; (b) Graphical representation of the data analysis procedure. 


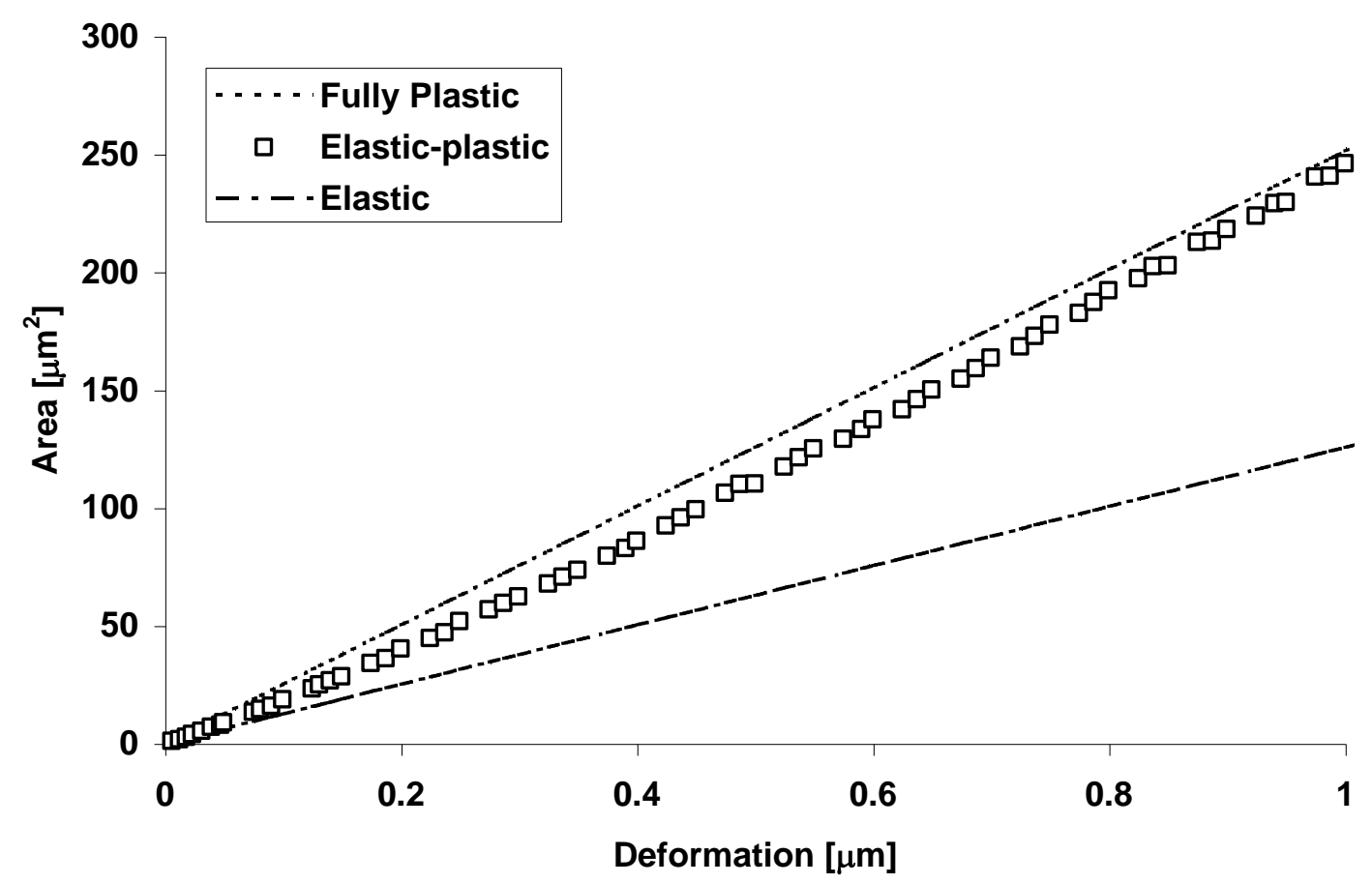

(a)

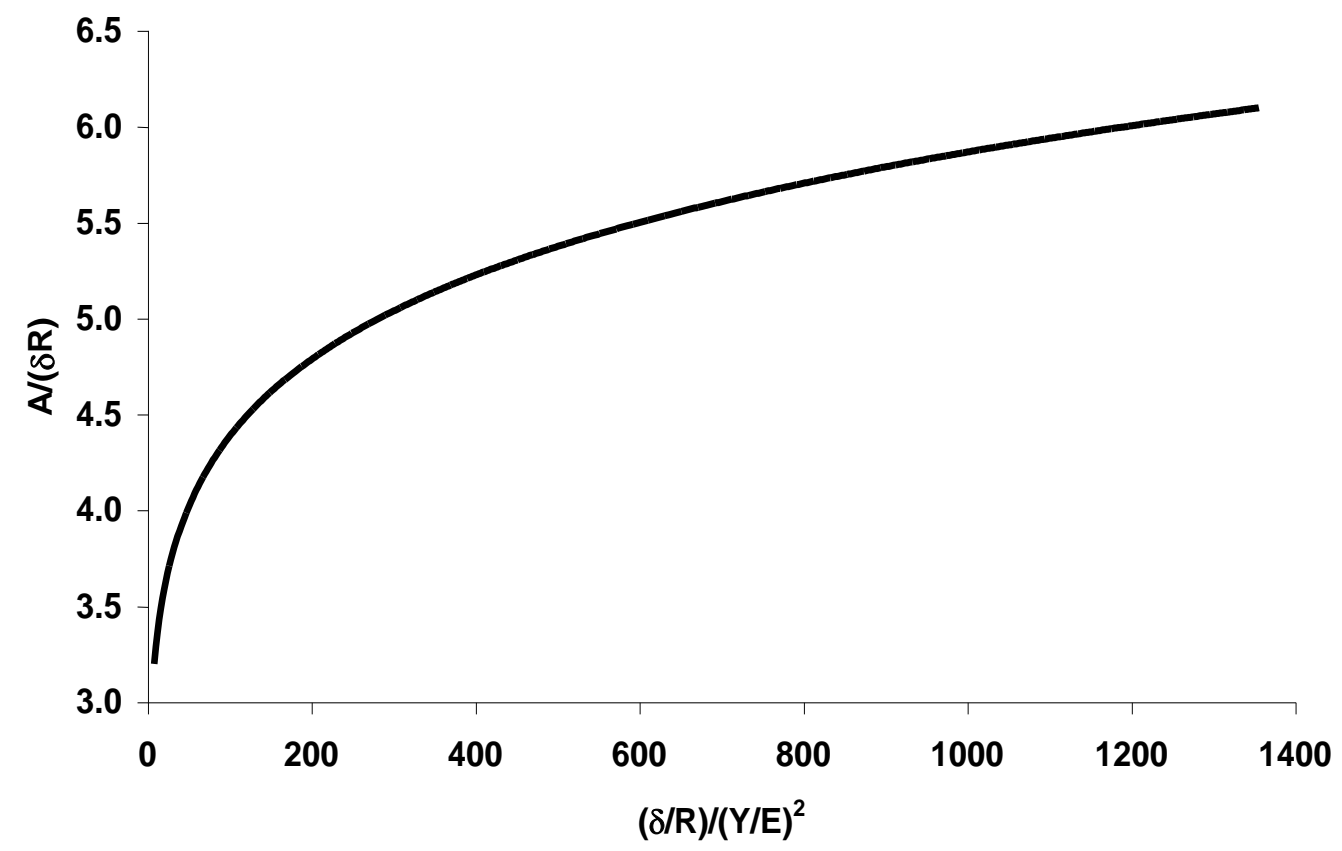

(b)

Figure 3. Results of the finite element analysis: (a) Variation of contact area with deformation and, (b) Variation of non-dimensional contact area $\frac{A}{\delta R}$ with non-dimensional deformation $\frac{\delta / R}{(Y / E)^{2}}$, in the elastic-plastic region. 


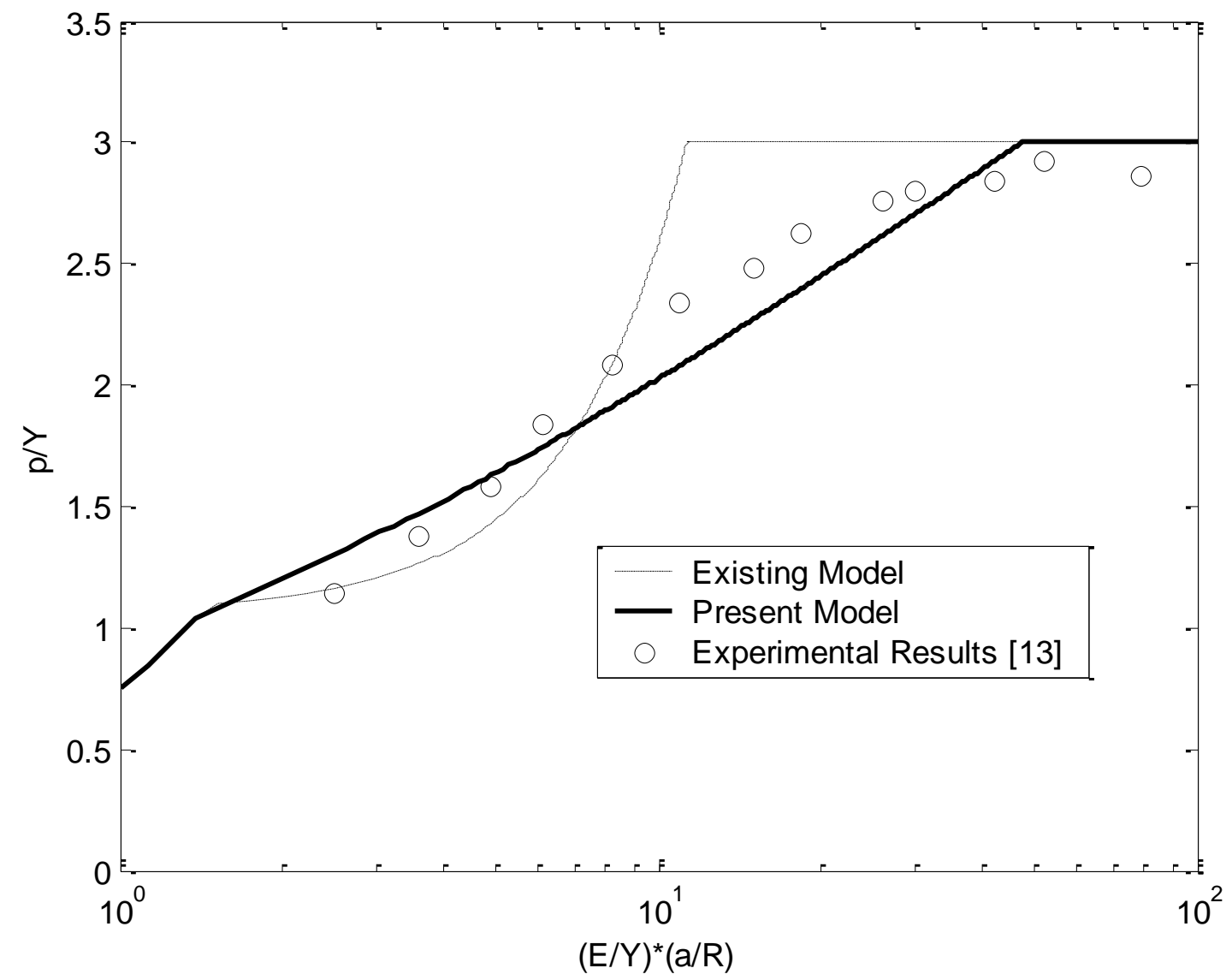

Figure 4. Comparison of the present surface deformation model with the earlier model of Li et al. [10] and experimental results [13]. 


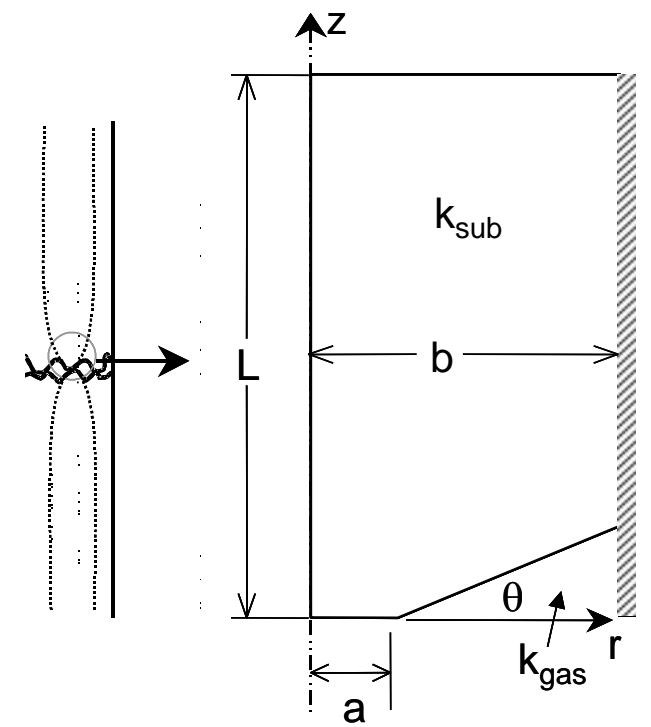

Figure 5. Semi-infinite cylinder terminating in the frustum of a cone. 


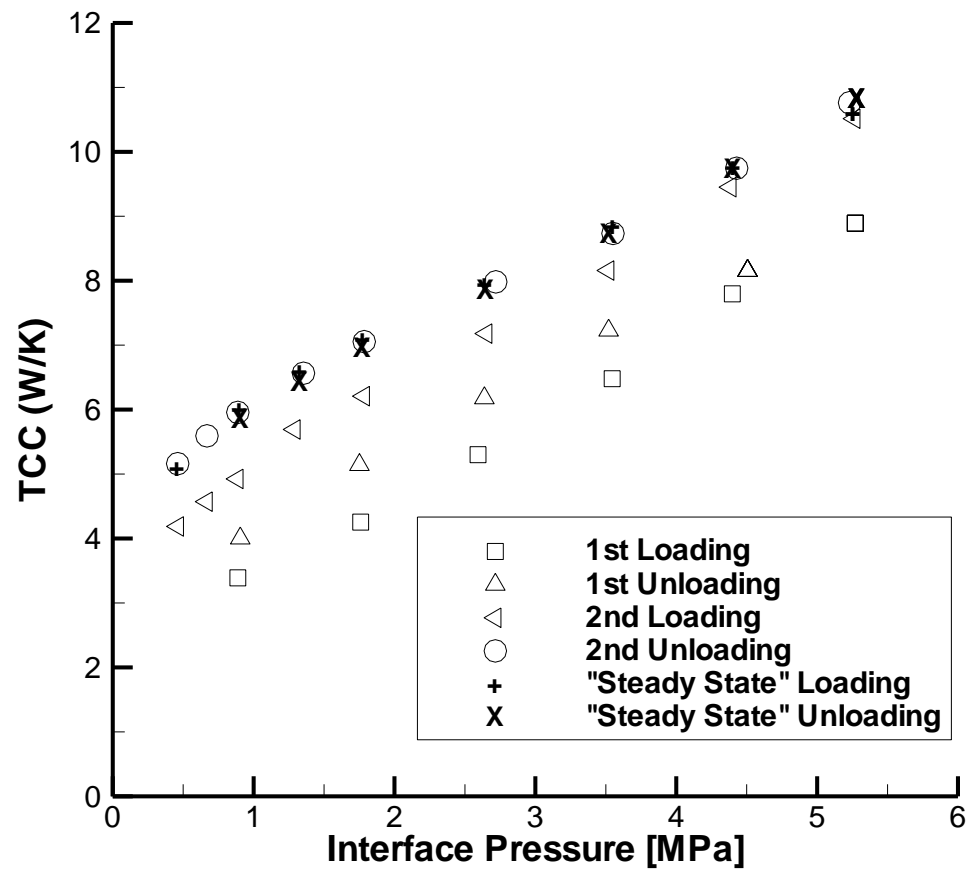

(a)

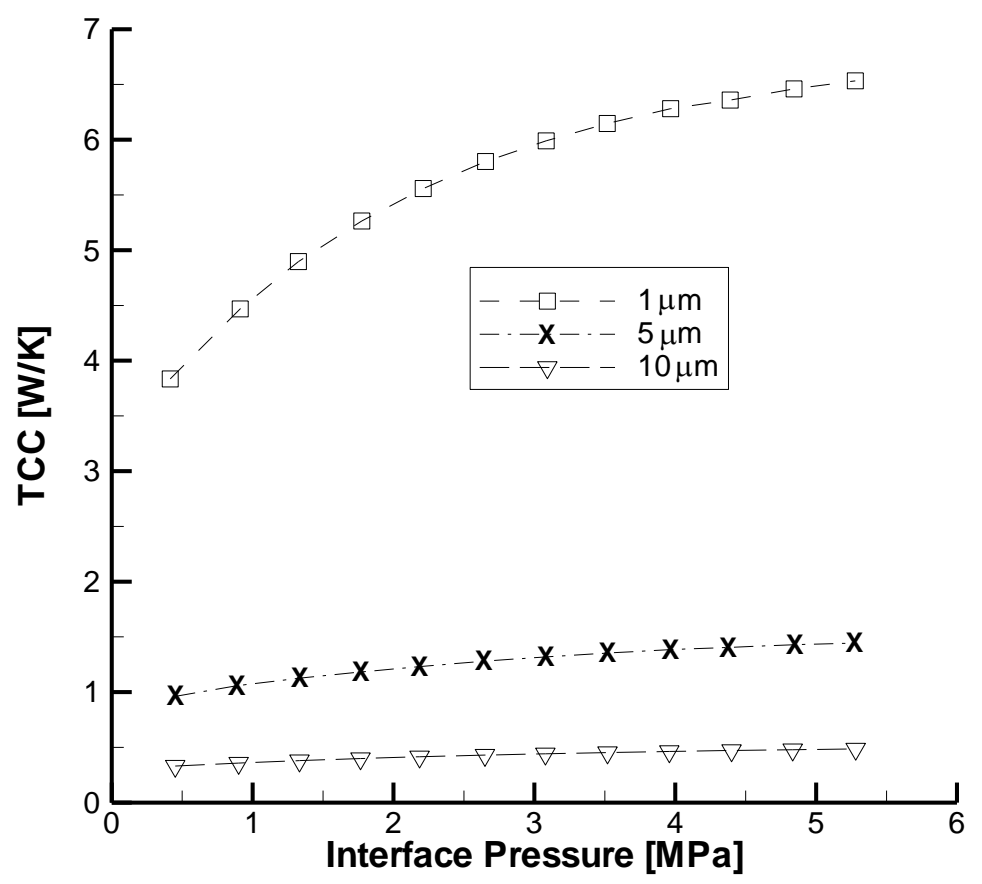

(b) 


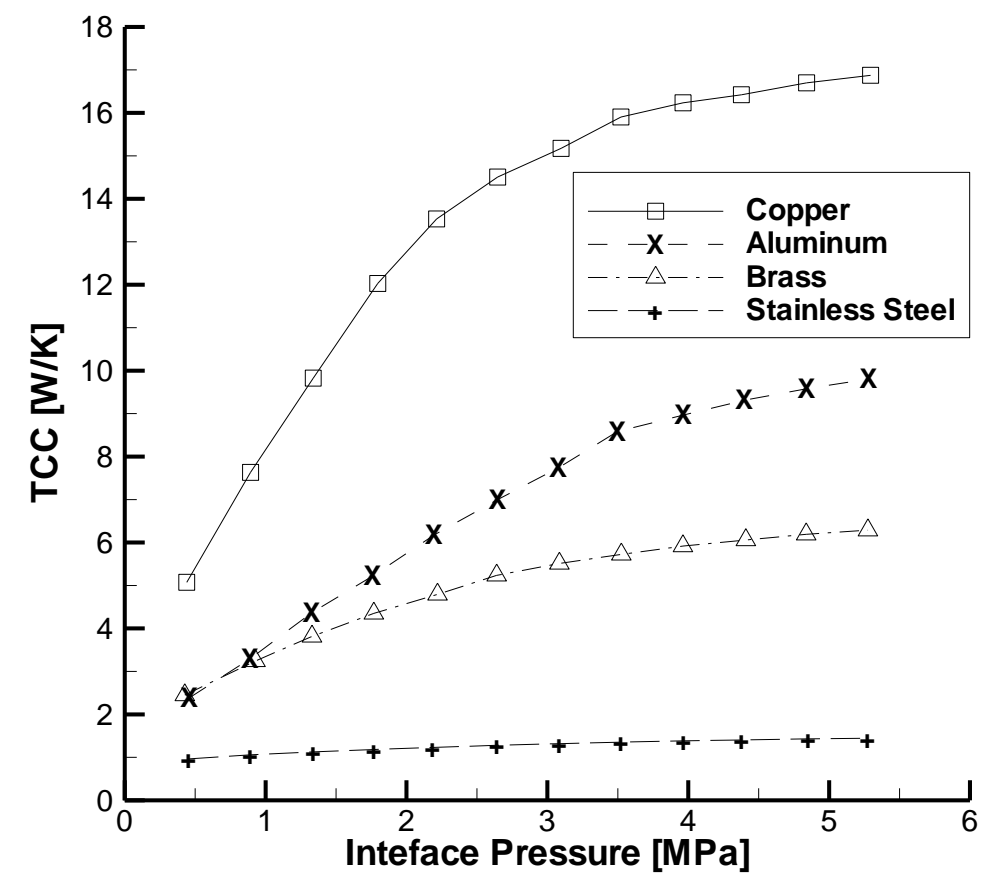

(c)

Figure 6. (a) Effect of loading-unloading cycles on TCC between two nominally flat $0.5 \mu \mathrm{m} \mathrm{R}_{\mathrm{a}}$ aluminum 6061-T6 samples; (b) TCC for stainless steel-to-stainless steel bare contact with varying surface roughness; (c) TCC for bare contact between $5 \mu \mathrm{m} \mathrm{R}$ a surfaces for tests between similar materials. 


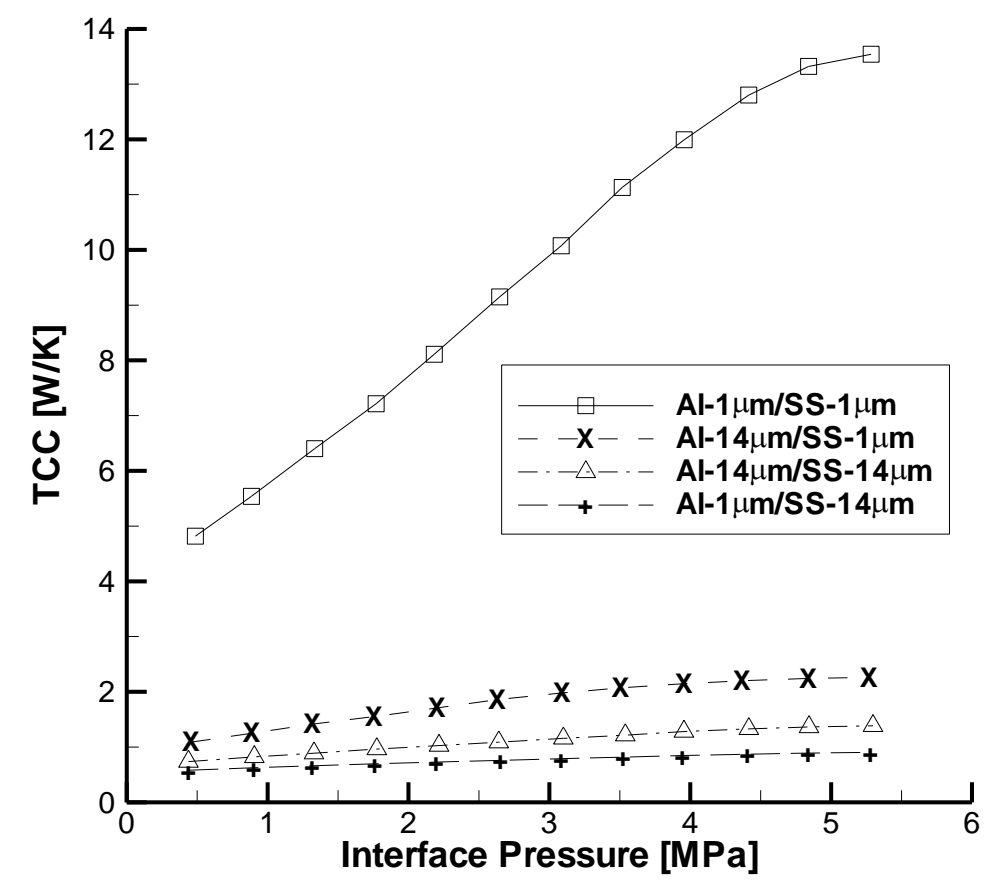

(a)

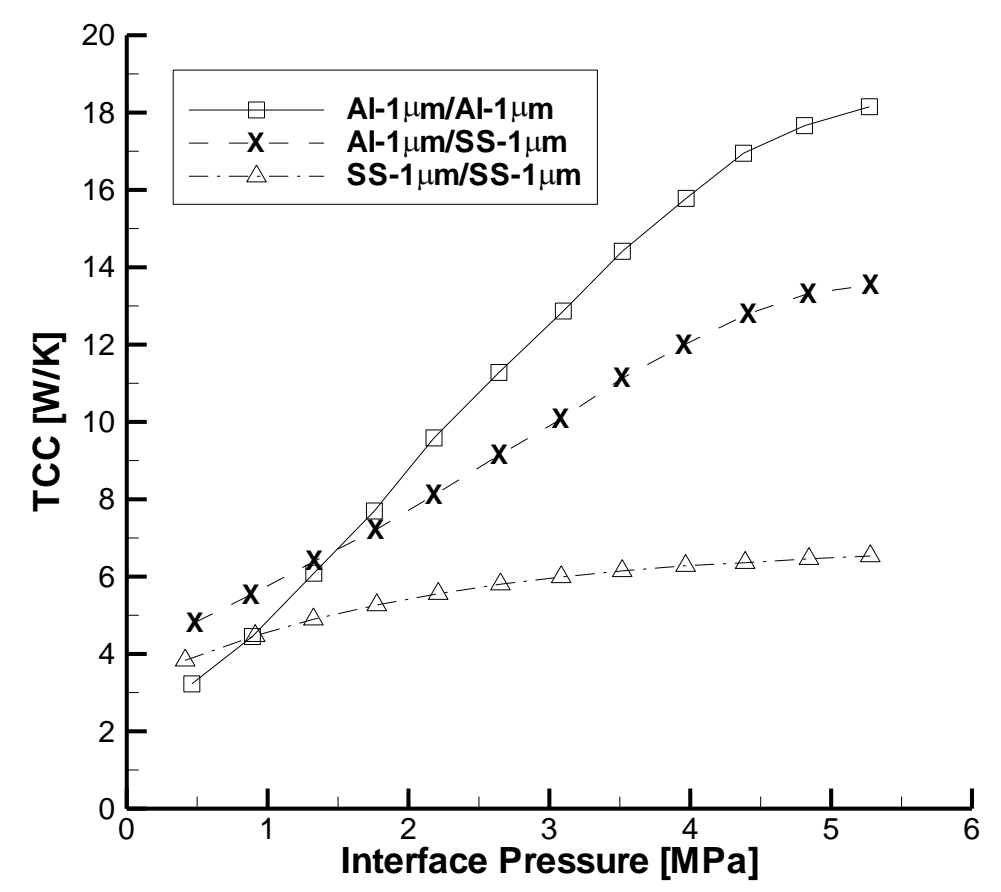

(b)

Figure 7. Thermal contact conductance for aluminum-to-stainless steel contact with an $\mathrm{R}_{\mathrm{a}}$ of (a) $1 \mu \mathrm{m}$ and $14 \mu \mathrm{m}$ and, (b) $1 \mu \mathrm{m}$ for both surfaces. 


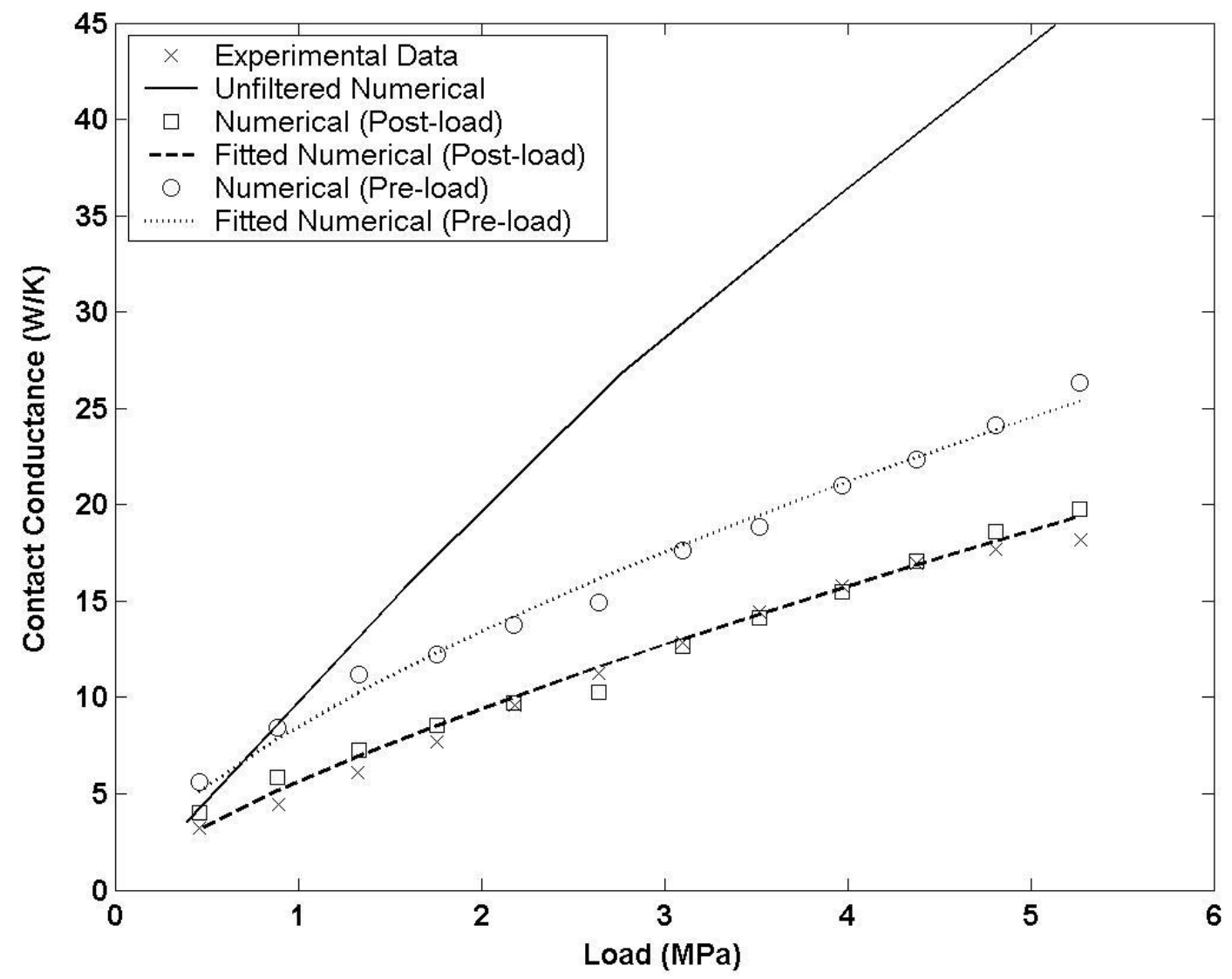

Figure 8. Comparison of experimental and predicted TCC values for aluminum-aluminum bare contact with $1 \mu \mathrm{m} \mathrm{R}$. 


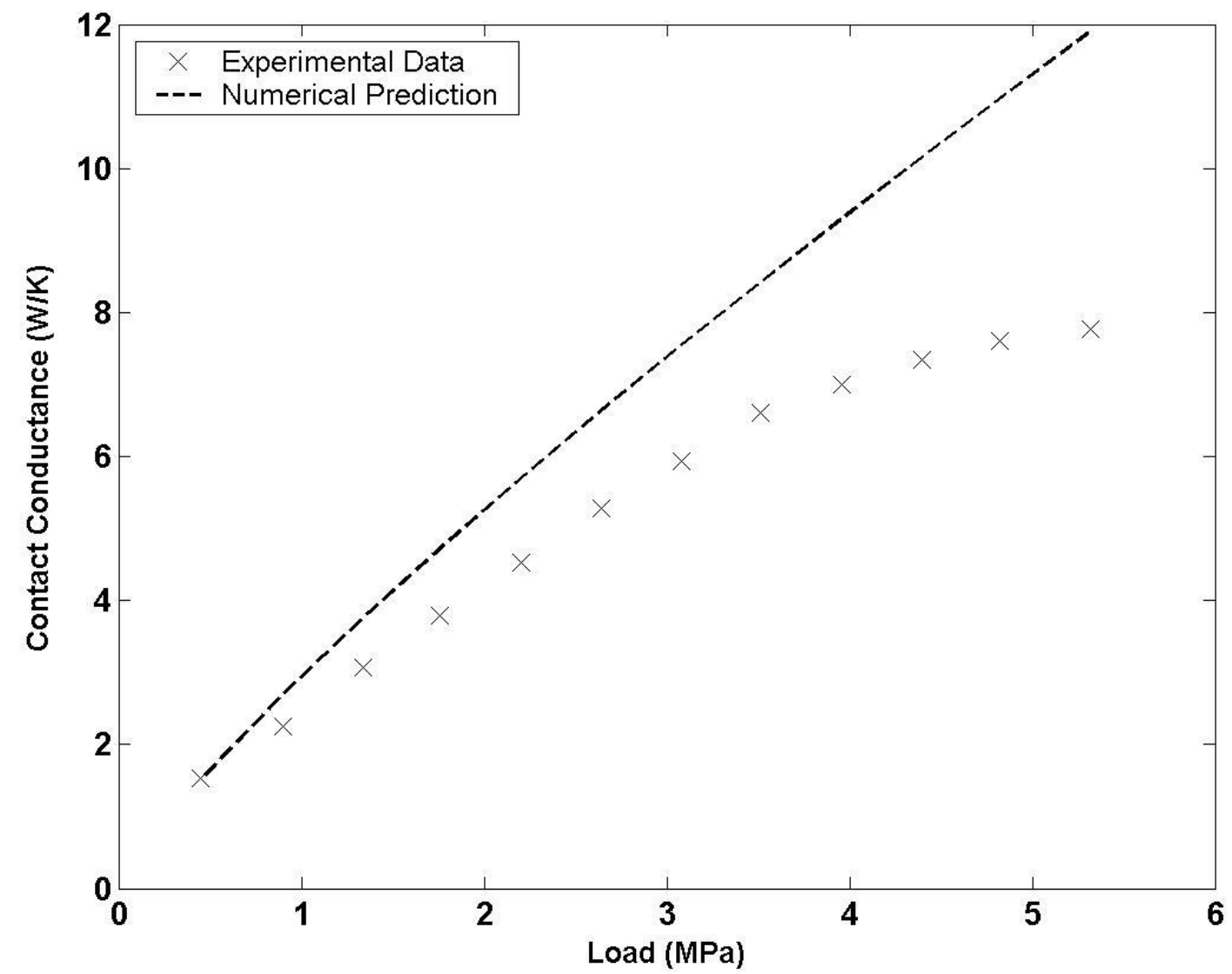

Figure 9. Comparison of experimental and predicted (with scans taken before and after loading) TCC values for aluminum-aluminum bare contact with $15 \mu \mathrm{m} \mathrm{R}_{\mathrm{a}}$. 


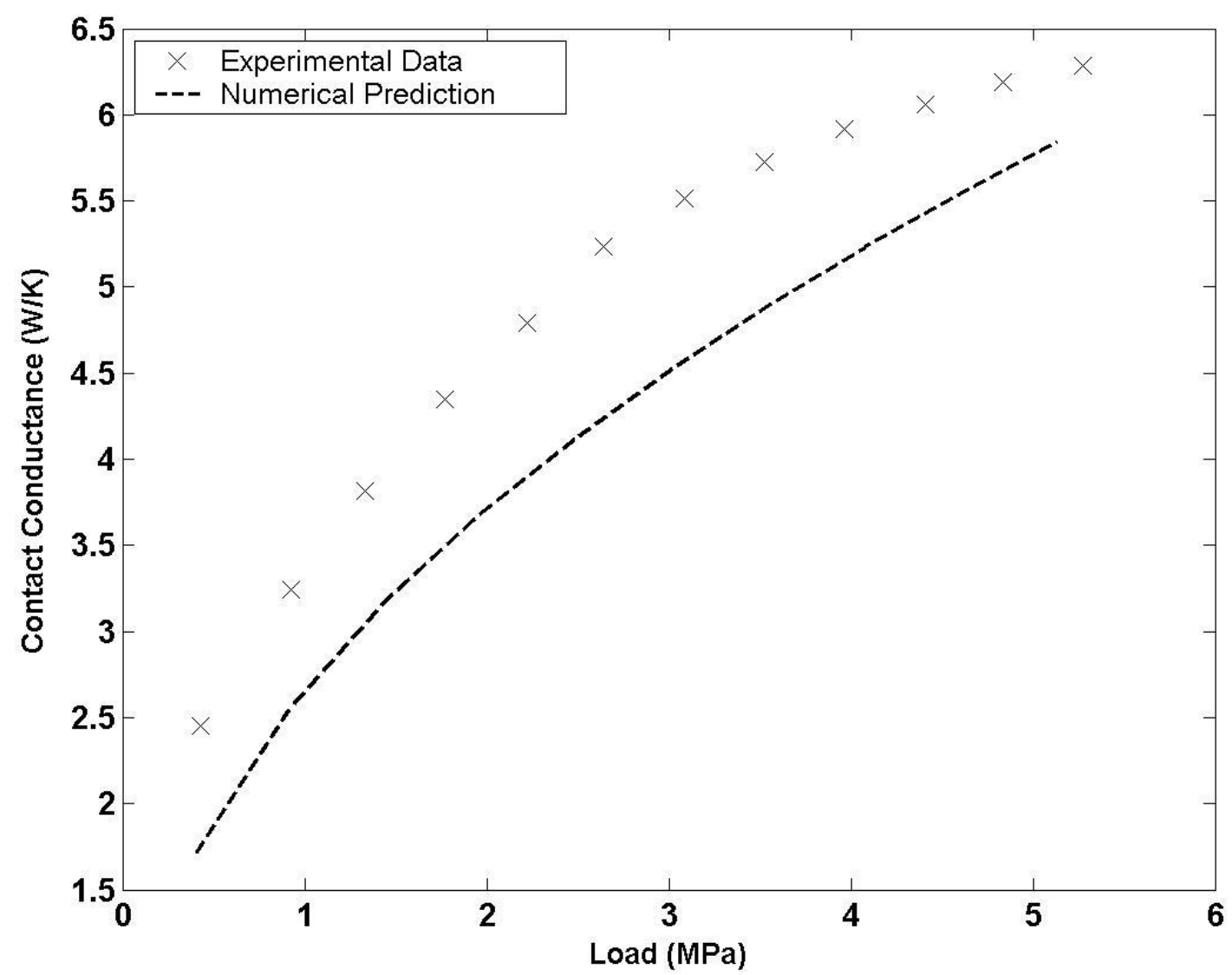

Figure 10. Comparison of experimental and predicted TCC values for brass-brass bare contact with $5 \mu \mathrm{m} \mathrm{R}$. 


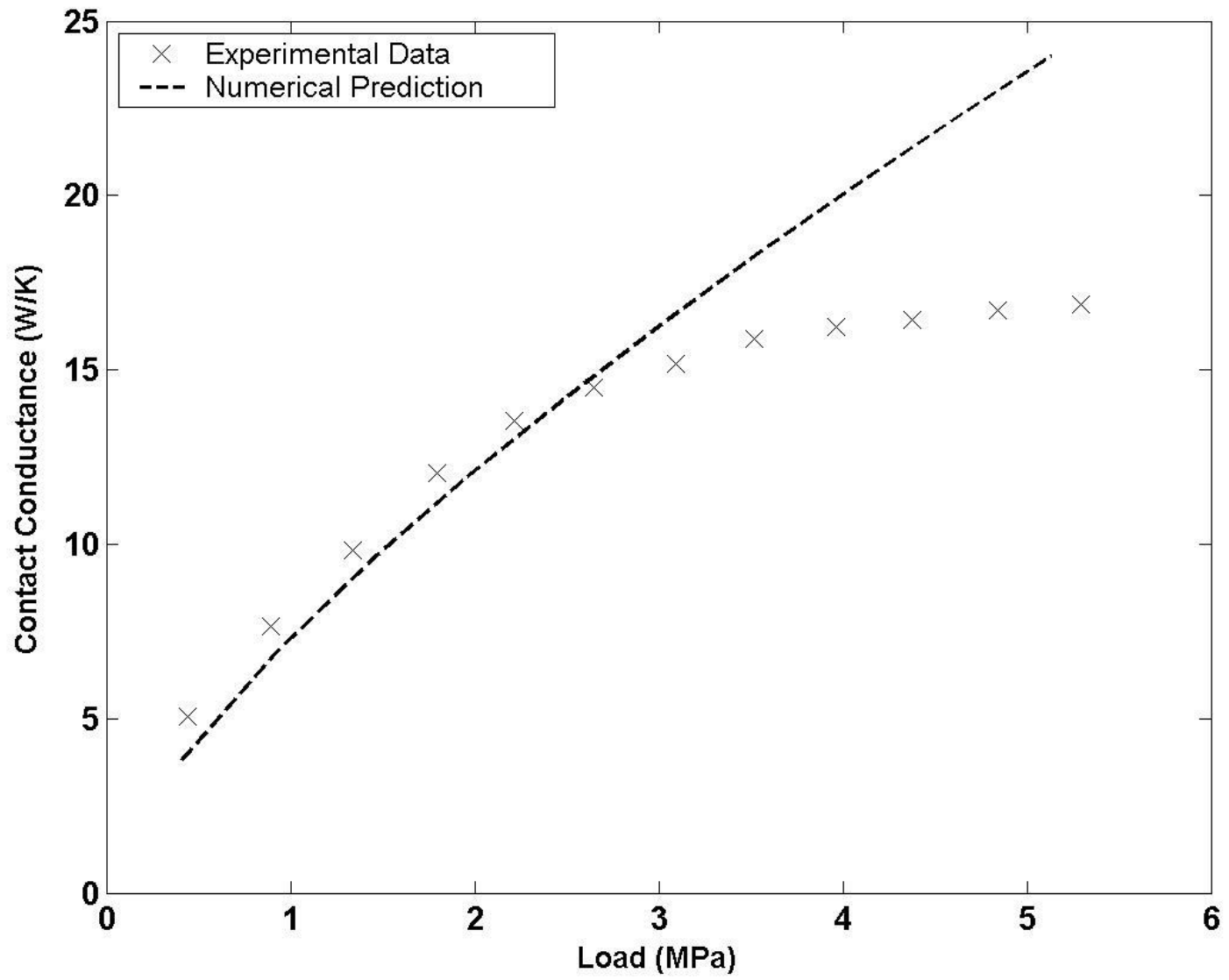

Figure 11. Comparison of experimental and predicted TCC values for copper-copper bare contact with $5 \mu \mathrm{m} \mathrm{R}$. 


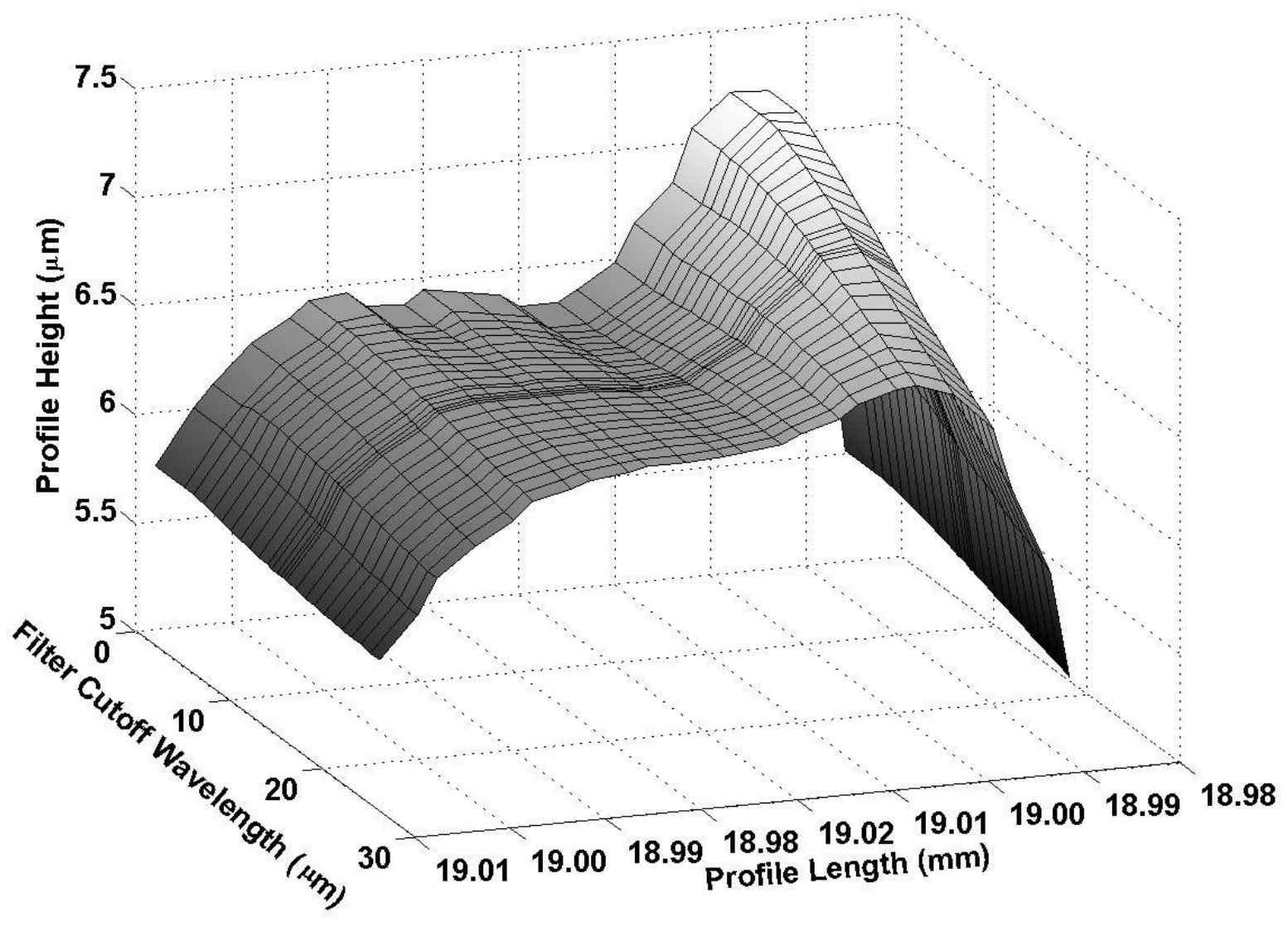

Figure 12. Variation in profile heights and radii of curvature due to filtering the profile data. 